\title{
Consumer Perception and Purchase Intention towards Smartwatches
}

\author{
Dr. P. Kishore Kumar ${ }^{1}$, V. Venkateshwarlu ${ }^{2}$ \\ ${ }^{1,2}$ Associate Professor, Department of Management SVS Group of Institutions Bheemaram Hanamkonda, \\ Warangal Telangana State
}

\begin{abstract}
The smartwatches is an innovative gadget launched in the recent years. This paper describes about the perception and purchase intention of consumers about smartwatches. A structured questionnaire had been used for primary data collection and statistical tools like descriptive statistics and frequency analysis have been used for data analysis. It is found from this study people who are aware about smartwatches are having positive purchase intention. This paper helps the marketers to design effective marketing strategies with regard to smartwatches.
\end{abstract}

Keywords: Smartwatches, purchase intention, perception, attitude, wearable

\section{Introduction}

The technological advancements in the recent years have changed the functionality of electronic products. The traditional mobile phones have become smartphones and similarly watches have become smartwatches. A smartwatch is a wearable device with features like smartphone in addition to its basic functionality like a watch. The smartwatch is synchronized with smartphone so that it can used to attend mobile calls, access notification alerts and used to store health records etc. In the modern world, smartwatch is one of the high technology products. By 2021the smartwatch shipments grow at an annual rate of 18 percent and may reach 70 million units (Beaver, 2016). It is also anticipate that Apple will continue to drive a large portion of the overall market, however, Android wearable devices will quickly catch up as emerging markets begin to adopt the technology. The top five vendors of smartwatches are Apple, Samsung, Lenovo, LG Electronics and Garmin etc (IDC, 2016). The research about consumer perception and behavior about smartwatches is in beginning stage and the present study is an attempt to fulfill the research gap. The primary aim of this study is to provide knowledge for marketers of smartwatches, academicians and researchers.

\section{Literature Review}

Smartwatches is in early stage of diffusion and perceived usefulness and visibility are important factors for adoption of smartwatches (Chuah, Rauschnabel, Krey, Nguyen, Ramayah, \& Lade, 2016). The ease of use is more important factor for enhancing consumers' attitude and adoption intention towards smartwatches. Further gender does not play a vital in adoption intention of smartwatches (Wu, Wu, \& Chang, 2016). According to Choi and Kim (2016) smartwatch is fashion product and consumers who need uniqueness are more interested to use smartwatch. (Choi \& Kim, 2016). Consumers give more importance to features of smartwatches than brand image and price of the product (Jung, Kim, \& Choi, 2016). The behavioral intention of smartwatch users is negatively influenced by privacy risk because smartwatches collects lot of physical activity data during usage.

The smartwatch had also being used for helping to consumers from the perspective of health and medical related applications (Kalantarian \& Sarrafzadeh, 2015). Many researchers have developed their research models based on technology acceptance model (TAM), unified theory of acceptance and use of technology (UTAUT), theory of planned behavior (TPB) and innovation diffusion theory (IDT) etc. Smartwatch is often referred as wearable technology product and also high technology product in the present era. According to Kim (2016) among round screen and square screen of smartwatches, the users prefer round screen smartwatches. At the same time controlling features are more convenient on square screen smartwatches (Kim, 2016). According to Kim and Shin (2015) the cost and sub-cultural appeal have an impact on consumers' attitude and intention to use regarding smartwatches. (Kim \& Shin, 2015)

\section{Research Methodology}

A structured questionnaire had been used for collecting primary data and the sample size is 130 . Multistage random sampling method had been implemented while collecting primary data. In first stage the respondents were enquired about their awareness smartwatch. In second stage only respondents who are aware about smartwatches are given opportunity to participate in the survey. The SPSS software version 20.0 had been used for data analysis. The frequency analysis and descriptive statistics had been used for data analysis. The items related to perception, norms, attitude and purchase intention were measured on 5-point Likert type scale. 
The first part of the questionnaire collects data about demographic profile with three variables like age group, gender and occupation. In second part of the questionnaire 9 items were used. The items which are measured with 5-point Likert type scale are shown in Table 5.

\section{Data Analysis}

Out of 130 respondents 70 percent are female and 30 percent are male. The detailed demographic profile is shown in Table 1. Large portion of the respondents belong to '20-29 years' age group. Out of total respondents 38.5 percent of the respondents are employees and 34.6 percent are students. It is observed from Table 2, that majority of the respondents are thinking Smartwatch is 'want' i.e. 48.5 percent and approximately 20 percent are treating it is as 'need'.

Table 1: Demographic Characteristics of Respondents

\begin{tabular}{|c|c|c|c|}
\hline S.No & Variable & Characteristic & Percent \\
\hline \multirow[t]{2}{*}{1} & \multirow[t]{2}{*}{ Gender } & Male & 30.0 \\
\hline & & Female & 70.0 \\
\hline \multirow[t]{4}{*}{2} & \multirow[t]{4}{*}{ Age group } & $20-29$ Years & 41.5 \\
\hline & & $30-39$ Years & 37.7 \\
\hline & & $40-49$ Years & 17.7 \\
\hline & & Above 49 Years & 3.1 \\
\hline \multirow[t]{4}{*}{3} & \multirow[t]{4}{*}{ Occupation } & Employee & 38.5 \\
\hline & & Self-employed & 22.3 \\
\hline & & Student & 34.6 \\
\hline & & Others & 4.6 \\
\hline
\end{tabular}

Source: Primary data

Table 2: Perception about Smartwatches

\begin{tabular}{|l|l|l|}
\hline & Frequency & Percent \\
\hline Both need and want & 40 & 30.8 \\
\cline { 2 - 3 } Need & 27 & 20.8 \\
\cline { 2 - 3 } Want & 63 & 48.5 \\
\cline { 2 - 3 } Total & $\mathbf{1 3 0}$ & $\mathbf{1 0 0 . 0}$ \\
\hline
\end{tabular}

Source: Primary data

According to Table 3 it is found that 13.8 percent of respondents have stated that 'easy music or video selection' is attractive feature of smartwatches. Majority of the respondents stated that notification alerts is more attractive feature i.e. 37.7 percent and approximately 30 percent stated opined that smartwatches are fashionable. According to Table 4 it can be stated that majority of the respondents i.e. 51.5 gained knowledge about smartwatches through internet followed by friends and family which is approximately 27 percent.

Table 3: Opinion about Smartwatches

\begin{tabular}{|l|l|l|}
\hline & Frequency & Percent \\
\hline Easy music or video selection & 18 & 13.8 \\
\cline { 2 - 3 } Fashionable & 38 & 29.2 \\
\cline { 2 - 3 } More convenient & 25 & 19.2 \\
\cline { 2 - 3 } Notification alerts & 49 & 37.7 \\
\cline { 2 - 3 } Total & $\mathbf{1 3 0}$ & $\mathbf{1 0 0 . 0}$ \\
\hline
\end{tabular}

Source: Primary data

Table 4: Source of information

\begin{tabular}{|l|l|l|}
\hline & Frequency & Percent \\
\hline Friends and Family & 35 & 26.9 \\
\cline { 2 - 3 } Internet & 67 & 51.5 \\
\cline { 2 - 3 } News paper ads & 10 & 7.7 \\
\cline { 2 - 3 } $\begin{array}{l}\text { Others } \\
\text { Television advertisements }\end{array}$ & 8 & 6.2 \\
\cline { 2 - 3 } Total & 10 & 7.7 \\
\cline { 2 - 3 } & $\mathbf{1 3 0}$ & $\mathbf{1 0 0 . 0}$ \\
\hline
\end{tabular}

Source: Primary data

Table 5: Descriptive Statistics for Scale Items

\begin{tabular}{|l|l|l|l|}
\hline S.No & Items & Mean & SD \\
\hline 1 & How likely are you to purchase smartwatch in future? (Purcahse Intention) & 4.11 & 0.80 \\
\hline 2 & Smartwatch is essential for completing professional and personal tasks. (Personal Norm) & 3.95 & 0.83 \\
\hline 3 & My family and friends expects me to use Smartwatch (Social Norm) & 3.77 & 0.92 \\
\hline 4 & I like smart watch (Attitude) & 4.40 & 0.63 \\
\hline 5 & I believe that Smartwatches are reasonably priced (Price perception) & 3.72 & 1.03 \\
\hline 6 & In future I will purchase Smartwarch (Purchase Intention) & 4.07 & 0.84 \\
\hline
\end{tabular}

$*$ SD = Standard Deviation, Source: SPSS Output 
The mean value for purchase intention of smartwatch is 4.11 is shown in Table 5. It means that respondents agree to own a smartwatch in future. The mean value for personal norms with regard to smartwatches is 3.95 with standard deviation (SD) of 0.83 . The means value for social norms of respondents is 3.77 with SD of 0.92 . According to Table 5, the means value for attitude is 4.40 with SD of 0.63 . The mean value for future purchase intention is 4.07 and SD is 0.84 . The price perception mean value is 3.72 with SD 1.03 .

\section{Discussion And Conclusion}

Smartwatches are perceived as 'want' and consumers are likely to have smartwatches for notification alerts. Since smartwatches can be synched with smartphones the email, messages from social networking sites can be accessed through it. The internet had created lot of awareness about smartwatches than other media. It is also found from this study that consumers have opined that smartwatches can be used to complete personal and professional tasks very conveniently. The consumers are thinking that smartwatches are reasonably priced based on its features. From this study it can be concluded that consumers are likely own a smartwatch in future to perform variety of tasks. The results of this research are consistent with previous studies regard smartwatches.

\section{Limitations}

There are many other factors like perceived behavioral control and ease of use etc have not been considered in this study. In this study the perception of consumers who have already awareness are analyzed but there is chance that people who are educated about smartwatch may likely to purchase it.

\section{Future Research}

The customer satisfaction levels regarding wearable devices need to be studied in future. The users of smartwatches should be enquired about in different geographical locations. The impact of education level, gender and income level on consumer attitude towards smartwatches should be researched in future.

\section{References}

[1]. Beaver, L. (2016, September 27). THE SMARTWATCH REPORT: Forecasts, adoption trends, and why the market isn't living up to the hype. Retrieved January 9, 2017, from Business Insider: http://www.businessinsider.com/smartwatch-and-wearables-researchforecasts-trends-market-use-cases-2016-9? IR=T

[2]. Choi, J., \& Kim, S. (2016). Is the smartwatch an IT product or a fashion product? A study on factors affecting the intention to use smartwatches. Computers in Human Behavior, 63, 777-786.

[3]. Chuah, S. H.-W., Rauschnabel, P. A., Krey, N., Nguyen, B., Ramayah, T., \& Lade, S. (2016). Wearable technologies: The role of usefulness and visibility in smartwatch adoption. Computers in Human Behavior, 65, 276-284.

[4]. IDC. (2016, July 21). Worldwide Smartwatch Market Experiences Its First Decline as Shipments Fall 32\% in the Second Quarter of 2016, According to IDC. Retrieved January 9, 2017, from IDC: Analyze the Future: https://www.idc. com/getdoc.jsp? containerId=prUS41611516

[5]. Jung, Y., Kim, S., \& Choi, B. (2016). Consumer valuation of the wearables: The case of smartwatches. Computers in Human Behavior , 63, 899-905.

[6]. Kalantarian, H., \& Sarrafzadeh, M. (2015). Audio-based detection and evaluation of eating behavior using the smartwatch platform. Computers in Biology and Medicine , 65, 1-9.

[7]. Kim, J. K. (2016). Round or Square? How Screen Shape Affects Utilitarian and Hedonic Motivations for Smartwatch Adoption. Cyberpsychology, Behavior, and Social Networking , 19 (12), 733-739.

[8]. Kim, K. J., \& Shin, D.-H. (2015). An acceptance model for smart watches: Implications for the adoption of future wearable technology. Internet Research, 25 (4), 527-541.

[9]. Wu, L.-H., Wu, L.-C., \& Chang, S.-C. (2016). Exploring consumers' intention to accept smartwatch. Computers in Human Behavior, 64, 383-392. 